\title{
Porque é que o "Fluoreno" se Chama Assim, Quando Não Flui, e Nem Todas as Substâncias Que Cheiram Mal se Chamam "Bromo"?
}

\section{Bernardo Jerosch Herold*}

O Secretariado da IUPAC envia-me frequentemente perguntas sobre nomenclatura química recebidas pelas mais diversas pessoas. Assim, um dia, um estudante da Universidade de Edimburgo enviou à IUPAC um protesto contra a manutenção do nome comum "fluoreno" ou "fluoreno-9H" na nomenclatura IUPAC dos compostos orgânicos, em lugar dum nome que desejava que fosse mais sistemático. ${ }^{1}$ Mesmo assim, reconheceu que, eventualmente, uma alteração desse tipo podia ser complicada. No entanto, não deixou de lançar o desafio à IUPAC.

Respondi-lhe demonstrando que não seria apenas necessário eliminar 0 nome fluoreno da lista de "nomes triviais e semi-sistemáticos retidos"[1] da IUPAC, mas que, além disso, as próprias regras para a atribuição de nomes a ciclos fundidos teriam que ser alteradas de tal forma que, por um efeito dominó, resultaria uma ruína parcial do complicado edifício da nomenclatura IUPAC de compostos policíclicos, particularmente dos heterocíclicos [2]. Estas regras baseiam-se em propostas de A. M. Patterson de 1925 [3] e 1928 [4] que primeiro foram adoptadas, a título experimental, nos índices dos Chemical Abstracts da Sociedade Americana de Química. Só depois foi codificada e aperfeiçoada pela IUPAC através dum processo de discussão que demorou, acredite-se ou não, cerca de setenta anos, continuando, além disso, até ao presente no que diz respeito a regras de selecção dum "nome preferido", naqueles casos em que as regras permitem mais de um nome para uma dada estrutura [5]. Além de tudo mais, tive de explicar ao meu corres-pondente que os nomes derivados do nome do fluoreno já se cifram em muitos milhares, número que não para de crescer. A perspectiva

\footnotetext{
Instituto Superior Técnico

Universidade Técnica de Lisboa
}

de criar sinónimos novos para tantos nomes que já figuram nos índices e nas bases de dados mais variadas, só iria criar uma confusão enorme.

Até ali estava a cumprir os meus deveres de Secretário da Comissão Interdivisional de Terminologia, Nomenclatura e Símbolos da IUPAC. No entanto, o estilo irreverente e espirituoso do estudante picou-me. Achei graça à sua observação de que não achava que os variados compostos fedorentos com que já tinha lidado como estudante de química no laboratório, devessem, por isso, todos chamarem-se "bromo" ou algo de semelhante, demonstrando assim que conhecia o étimo grego de "bromo" ( $\beta \rho \omega \mu \mathrm{O} \zeta$, odor infecto) e que supunha que o nome do fluoreno derivasse do verbo latino "fluere", fluir. Embora a homofonia em inglês dos nomes do flúor "fluorine" e do fluoreno, "fluorene" que mencionou não tenha correspondência em português, nem em nenhuma língua, fora a inglesa, a questão que levantara não deixava de ser intrigante. Afinal, embora o flúor seja um gás à temperatura ambiente, e portanto capaz de fluir, não seria certamente isso que teria levado a lhe atribuir esse nome. Quanto ao fluoreno, também não é óbvio, à primeira vista, que possa haver uma relação com o "fluere" latino ou com o elemento flúor. Por outro lado, também não podia deixar de simpatizar com alguém que se revoltava contra o desrespeito da norma já enunciada por Morveau em 1782 "A denominação dum composto químico só é clara e exacta quando designa as partes constituintes com nomes em conformidade com a natureza dos mesmos."[6]

Voltaram então à minha memória os ensinamentos que tinha recebido no meu tempo de estudante sobre as origens dos nomes dos elementos, e fui verificar se me estava a recordar bem. Nessa verificação, utilizando as fontes mais completas e fiáveis, reconstrui a história destes nomes e propus-me a contá-la com mais algum pormenor.

O início da história recua no mínimo ao século 16 . Dessa altura datam os primeiros relatos circunstanciados escritos (em latim) sobre as artes mineiras e metalúrgicas que, até ali, eram transmitidas oralmente mais ou menos secretamente de pais para filhos, e de mestres para oficiais e destes, embora mais raramente, para os aprendizes. No grande arranque da civilização europeia com os descobrimentos marítimos e com figuras como Leonardo da Vinci, Michelangelo, Raffael, Dürer, Copérnico, Paracelso, Erasmo de Roterdão e Lutero, a impressão com tipos móveis fez com que uma pessoa, em vez de viver da prática dum ofício, pudesse fazer negócio com aquilo que até aí eram segredos desses ofícios, ao revelá-los em livros, imprimindo-os e vendendo-os. Quanto às artes mineiras e metalúrgicas, na Itália, esse papel foi desempenhado por Vanoccio Biringuccio (1480-1539) com a sua Pyrotechnia (Veneza 1540) e na Alemanha por Georg Agricola (1494-1555) com os seus escritos, em particular Bermannus sive de re metallica dialogus (Basileia 1530). Agricola descreveu minerais fundentes, isto é, que, devido à sua temperatura de fusão baixa e por formarem com certos minérios misturas (eutécticas, como só muito mais tarde foram designadas) de ponto de fusão ainda mais baixo possibilitam tornar fluidos os minérios às temperaturas que se podiam atingir nos fornos daquela época, e assim facilitar a sua redução ao estado metálico. O termo latino que utiliza para esses "addittamenta" dos minérios é "fluores", obviamente derivado do já mencionado verbo latino "fluere" [7,8]. Em 1599 foi publicado na Alemanha um livro de Alquimia com o título Triumphwagen Antimonii dum autor, que se concluiu ser fictício, Basilius Valentinus, alegadamente um monge que teria vivido cerca de um 
século antes. Supõe-se que seja uma compilação de vários manuscritos de autores desconhecidos do século 16 , ou simplesmente de textos forjados. Neste livro, em lugar da clareza, concisão e lucidez com que Biringuccio e Agricola descreveram as suas observações e instruções técnicas, defrontamo-nos com uma profusão verbal em que conhecimentos da época adquiridos nas minas, nas forjas, nas oficinas dos boticários e nas cozinhas dos alquimistas, eventualmente transcritos doutras fontes, são colocados no contexto da procura da pedra filosofal. Apesar de esta sobrecarga simbólica prejudicar o rigor e a fiabilidade da Química propriamente dita que aí se encontra, estes escritos tiveram o mérito, entre outros, de consagrar a designação genérica latina "fluores" para os minerais fundentes $[7,9,10]$.

O mais utilizado entre estes minerais (que funde entre 1200 e $1300{ }^{\circ} \mathrm{C}$, e que mais tarde se revelou como sendo constituído principalmente por fluoreto de cálcio) recebeu o nome de "fluorite" em várias línguas (além de vários outros nomes "fluorspar" em inglês, "Flußspath" em alemão, "spath fusible', "spath fluor", "héspéros" e "fluorine" em francês). Wilhelm Scheele descobriu em 1771 que, na reacção da fluorite com o ácido sulfúrico concentrado, se libertava um ácido a que não atribuiu nenhum nome. Lavoisier designou-o em 1789 por "acide fluorique", Priestley chamou-Ihe em 1790 "fluor acid air". Ampère escreveu em 1810, numa carta a Davy que suspeitava da existência dum elemento análogo ao cloro que se devia poder obter por electrólise deste ácido, e sugeriu que esse elemento se devia chamar "fluorine", em analogia com o nome inglês do cloro "chlorine". As dificuldades desta electrólise foram, no entanto, tantas, que só em 1886 é que Moissan as venceu, e preparou o elemento a que chamou em francês "fluor", prescindindo da desinência "ine" que nunca teve grande aceitação para os nomes dos halogénios do lado de cá do Canal da Mancha $[7,10]$.

Mas terá o nome do fluoreno algo a ver com o nome do flúor? A resposta é afirmativa, mas a sua explicação obriga a mais uma divagação.
O itinerário iniciado com os "fluores" do fictício Basilius Valentinus continua na Mineralogia com a observação de que algumas variedades de fluorite, ao serem expostas à luz do dia, emitem uma bela cor azul. Por este fenómeno ter sido primeiro observado na fluorite, o mesmo recebeu o nome de "fluorescência" [10].

O último elo da cadeia que liga os "fluores" ao nome do fluoreno foi o facto de Marcellin Berthelot, ao isolar do alcatrão de hulha e descrever um novo hidrocarboneto em 1867, ter observado que as soluções alcoólicas diluídas do mesmo exibiam uma fluorescência forte (embora fraca na forma cristalina). Foi essa a razão de Ihe ter dado o nome de "fluoreno" [11].

Entre a fluorescência da fluorite e a fluorescência do fluoreno há, no entanto, uma diferença essencial: enquanto o fluoreno puro fluoresce, o fluoreto de cálcio puro não fluoresce de todo. A fluorescência das fluorites, e aliás as suas belas e variadas cores, são devidas a contaminações com traços ínfimos de vários metais ou a defeitos da rede cristalina produzidos por radiações ionizantes.

A determinação da estrutura da molécula de fluoreno ainda levaria alguns anos. Berthelot é conhecido como um acérrimo defensor do "equivalentismo" contra o "atomismo", e portanto terá sido um dos mais renitentes a aceitar a estrutura do fluoreno. Quando finalmente essa estrutura foi determinada em 1878 por R. Fittig, só passados bastantes anos, teve aceitação geral (foi preciso vencer a resistência dos "anti-atomistas"). Entretanto o nome "fluoreno" já se tinha enraizado de tal forma que era difícil substitui-lo por outro mais sistemático. O tratado de Beilstein [12] ainda propôs como alternativa "o-difenilenometano"2, nome que, não se enquadrando no admirável sistema imaginado por Patterson e adoptado pela IUPAC, raríssimas vezes foi usado, e acabou por cair no esquecimento.

Este exemplo ilustra quanto é complicado responder a perguntas, aparentemente simples, sobre a "razão dos nomes". Como a atribuição de nomes tem sempre uma componente arbitrária, em rigor, nunca pode haver uma resposta completa a este tipo de perguntas. Para encontrar uma resposta parcial, não há outro processo que não seja o de procurá-la na História da Química e, pelo caminho, ir aprendendo alguns factos curiosos reveladores do pensamento característico de diferentes épocas da História e da maneira como nestas se criou conhecimento novo.

\section{NotAs}

${ }^{1}$ O seguinte texto é a transcrição da parte relevante do original inglês da mensagem: "To my mind, it seems silly to name this compound fluorene. It is homophonic with fluorine, $F$, a completely different chemical. While they both may come from the Latin "fluere", to flow, I have encountered many chemicals with this property during my brief time as a student of chemistry, just as I have used a variety of malodorous chemicals without feeling that they should all be known as "bromine" or similar!

Though IUPAC is primarily interested in "standardizing", it seems implicit to me that the fundamental objective of standardization is to avoid confusion, which can only be engendered through practices such as this. This seems especially relevant as chemistry tends towards greater inter-disciplinary co-operation, with inorganic, organic and physical chemists all working in concert towards common goals.

While I imagine that changing the name of even a relatively obscure chemical is a massive task, with the potential to cause even more uncertainty than any current ambiguity, this seems a perfect opportunity for the IUPAC to intercede."

2 Em alemão "o-Diphenylenmethan".

\section{REFERÊNCIAS}

[1] Guia IUPAC para a Nomenclatura de Compostos Orgânicos, Tradução Portuguesa nas Variantes Europeia e Brasileira, Lidel - Edições Técnicas, Lda. Lisboa 2002 (R. Panico, W. H. Powell, J.-C. Richer, A Guide to IUPAC Nomenclature of Organic Compounds Recommendations 1993, Blackwell Scientific Publications, Oxford 1993) Tradução de A. C. Fernandes, B. Herold, H. Maia, A. P. Rauter, J. A. R. Rodrigues. ISBN 972-757-150-6.

[2] G. P. Moss et al., "Nomenclature of Fused and Bridged Fused Ring Systems (Recommendations 1998)", Pure Appl. Chem. 70 (1998) 143-216. Acessível em www.chem.qmul.ac.uk/iupac/ fusedring/ 
[3] A. M. Patterson, J. Amer. Chem. Soc. 47 (1925) $543-561$.

[4] A. M. Patterson, J. Amer. Chem. Soc. 50 (1928) $3074-3087$

[5] P. E. Verkade, A History of the Nomenclature of Organic Chemistry, D. Reidel, Dordrecht for Delft University Press 1985, ISBN 90-277-1643-9.

[6] Citado conforme a tradução de A. M. Nunes dos Santos, Prefácio, Reforma e Revolução, na edição facsimilada do original de Nomenclature Chimique (1978) de Morveau, Lavoisier, Berthollet e Fourcroy, Edição exclusiva de Petrogal, S. A., Lisboa, 1992.

[7] J. R. Partington, A History of Chemistry, Vol. II, McMillan, London 1961.

[8] E. Darmstaedter in G. Bugge, Das Buch der Grossen Chemiker, Band I, $6^{a}$ reimpressão inalterada da $1^{a}$ edição 1929 , Verlag Chemie, Weinheim 1984.
[9] F. Fritz in G. Bugge, loc. cit

[10] Gmelins Handbuch der Anorganischen Chemie, 8. Auflage, Verlag Chemie, Weinheim, Leipzig, 1926. Systemnummer 5

[11] J. R. Partington, Ioc. cit. Vol. IV, 1964

[12] Beilsteins Handbuch der Organischen Chemie, 4. Auflage, 5. Band, Springer, Berlin 1922.

\section{Curiosidades Científicas}

\section{Electrónica de Plástico}

Em paralelo com a electrónica convencional baseada no silício, que na crescente ânsia de colocar cada vez mais componentes num chip de alguns milímetros quadrados, está à beira de atingir os limites do fisicamente possível, está a emergir um novo paradigma baseado, não no elevado desempenho e miniaturização dos componentes, mas sim no baixo custo de fabrico.

De facto, os circuitos electrónicos actuais, que estão nos chips dos nossos computadores, já têm componentes com dimensões da ordem das dezenas de nanómetros (1 nanómetro $=0,000000001 \mathrm{~m}$ ), aproximando-se assim das dimensões dos próprios átomos. Essa tendência de miniaturização que vem desde pouco depois da criação do circuito integrado, mais precisamente desde 1965, é conhecida por lei de Moore e mostra que a evolução da miniaturização é de uma grande regularidade: o número de componentes duplica cada cerca de 18 meses, atingindo actualmente as centenas de milhões de transístores por chip. Essa regularidade é uma das razões do grande sucesso da indústria electrónica, pois permite fazer previsões a longo prazo, incentivando grandes investimentos, sem risco.

A electrónica de plástico, também chamada electrónica orgânica, assenta no baixo custo do processamento e na possibilidade de manipulação química para atingir as propriedades desejadas nos materiais. Uma vez que os semicondutores orgânicos

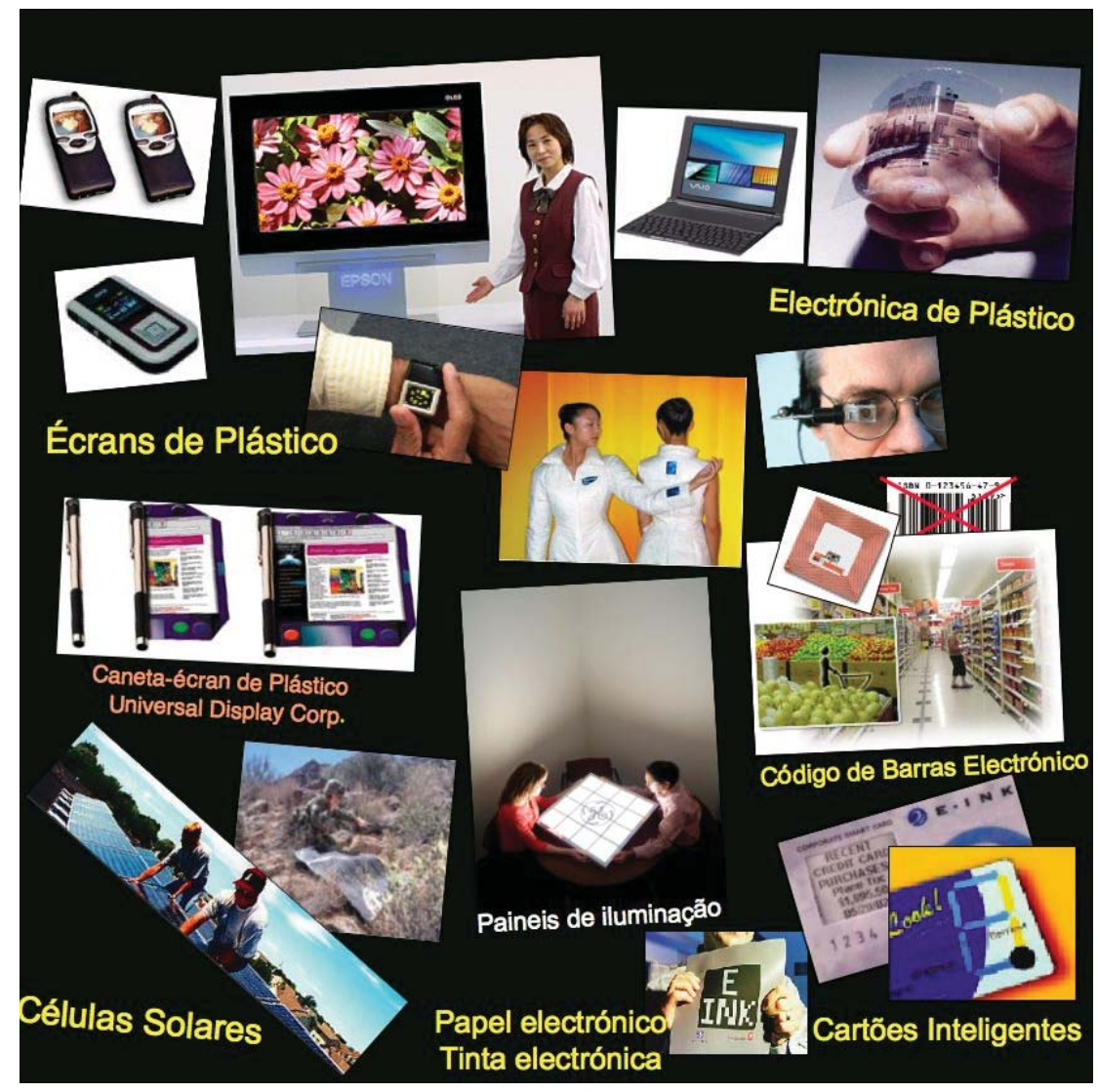

podem ser concebidos de modo a serem solúveis em solventes comuns, podem ser usadas tecnologias de produção como impressão a jacto de tinta ou estampagem. Um dos objectivos mais ambiciosos para produzir circuitos e dispositivos electrónicos de baixo custo baseia-se no uso de impressoras rotativas de alta velocidade (como as usadas para imprimir os jornais), que podem imprimir milhares de circuitos ou dispositivos por metro quadrado que depois podem ser separados por processos automáticos. O uso de substratos flexíveis de plástico ou papel permite atingir custos extremamente baixos para certos tipos de circuitos como os que futuramente irão substituir o actual código de barras. O uso de códigos de barras electrónicos (etiquetas de identificação por radiofrequência, ou radiofrequency identification tags, RFIDs) permitirá que, por exemplo, num supermercado, as compras sejam automaticamente facturadas ao passar pela caixa, sem necessidade de as tirar do carrinho, como se fora uma Via Verde. Os dispositivos da Via Verde são muito mais complexos e feitos com uma tecnologia muito mais sofisticada e cara. No caso dos RFIDs de plástico, o custo de fabrico previsto é de 1 cêntimo por etiqueta. 
Com tecnologia semelhante, baseada em dispositivos emissores de luz (organic light-emitting diodes, OLEDs) feitos com materiais orgânicos electroluminescentes, podem fazer-se ecrãs flexíveis para as mais diversas aplicações como telemóveis, monitores para computadores e apareIhos de televisão, alguns dos quais já comercializados, por exemplo, pela Sony, no Japão [http://www.youtube. com/watch? $v=$ NcAm3KihFho\&featur $\mathrm{e}=$ related].

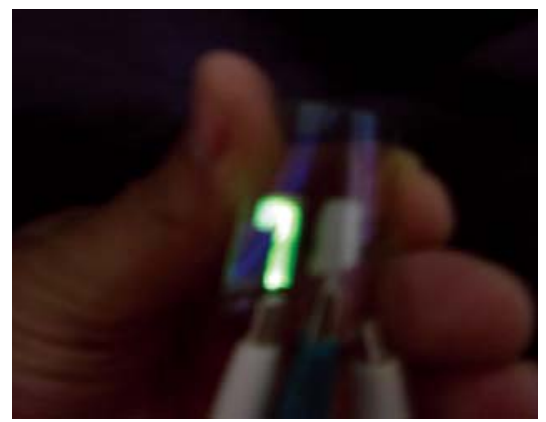

Figura 1 Um LED flexível

Outra aplicação da electrónica de plástico, que promete revolucionar a indústria de iluminação é o uso de OLEDs (de luz branca, se assim se quiser) em painéis de iluminação. As eficiências e tempos de vida já excedem os das lâmpadas incandescentes. A iluminação baseada nesta tecnologia possibilitará iluminação difusa, com painéis de grande área e cuja intensidade de iluminação pode ser controlada. Também existem $L E D$ s de materiais inorgânicos bastante eficientes, mas de muito maior custo de fabrico.

No âmbito do actual programa quadro europeu, FP7, estão em curso vários projectos de investigação e desenvolvimento, incluindo alguns de grande dimensão envolvendo consórcios de empresas, que se propõem desenvolver tecnologias com materiais orgânicos para produzir electrónica ao metro quadrado, podendo cada sistema incluir todo um conjunto de circuitos e dispositivos como sensores, actuadores, baterias e células solares, tudo em plástico flexível.

Os materiais semicondutores usados nesta tecnologia podem ser baseados em moléculas pequenas, como o pentaceno, representado na figura da esquerda e polímeros, consti- tuídos por muitas unidades ligadas entre si, formando cadeias, como os membros da família dos fluorenos, representados à direita.<smiles>c1ccc2cc3cc4cc5ccccc5cc4cc3cc2c1</smiles>

Pentaceno

Uma característica de todos estes materiais é a existência de duplas ligações conjugadas (ligações químicas alternadamente simples e duplas, como se pode ver nas estruturas representadas), que é, de facto, o segredo para que sejam condutores ou semicondutores, pois os electrões podem circular através destas ligações químicas. Nesta família de moléculas, $\mathrm{X}$ e $\mathrm{R}$ são cadeias de átomos, escolhidas, respectivamente, de modo a dar origem a diversas cores para a luz emitida (ver figura 2), e para fazer com que o material seja solúvel de modo a permitir processos de fabrico de dispositivos de baixo custo.

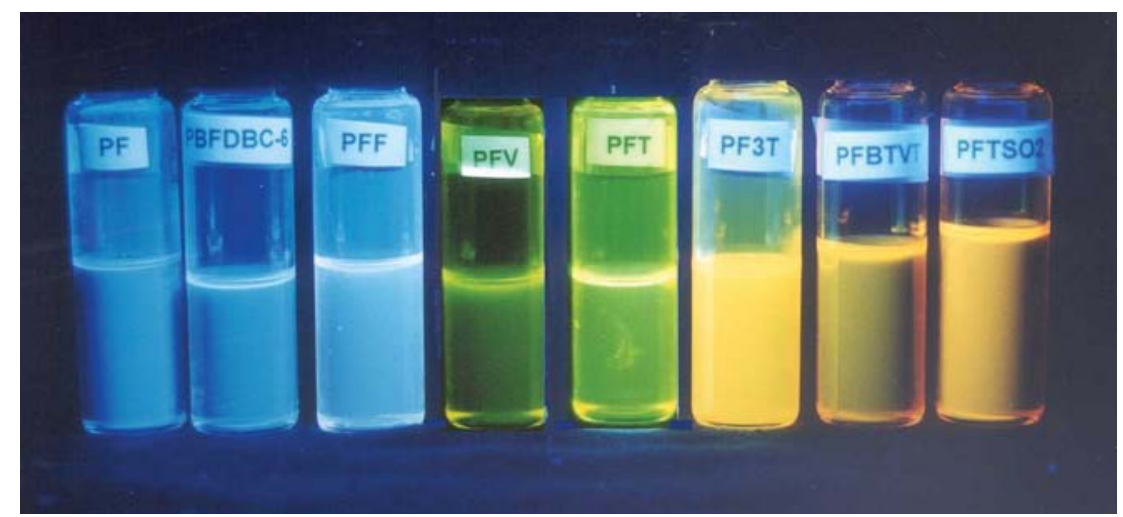

Figura 2 Controle da cor da luz emitida através da modificação da estrutura molecular do polifluoreno

A electrónica orgânica poderá ter, a breve prazo, grande impacto na vida das pessoas, proporcionar oportunidades de negócio, dar origem a novas pequenas e médias empresas, como já estão a aparecer na Europa central e do norte, e criar novos empregos, naturalmente, para pessoas qualificadas.

Só na área dos RFIDs as projecções apontam para volumes de negócio da ordem dos 250 mil milhões de euros em 2025, quase tanto como o de toda a actual indústria de semicondutores.

Curiosamente, ou talvez não, muita da investigação científica relevante

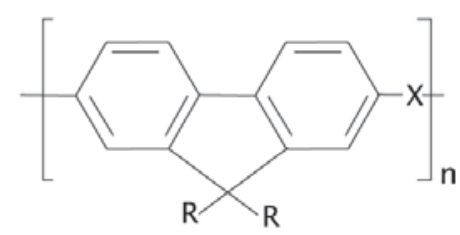

Polifluoreno

para esta tecnologia tem sido feita na Europa, enquanto que a produção e comercialização aparecem no extremo oriente (Japão, Coreia, Singapura, etc.), sendo muitos dos equipamentos desenvolvidos $\mathrm{e}$ produzidos nos Estados Unidos da América do Norte.

Luís Alcácer DEQB_IST

texto também disponível em:

http://dererummundi.blogspot.com/ 2008/03/electrnica-de-plstico.html 